\title{
Long term evaluation of corneal graft survival after lamellar Keratoplasty without limbal stem cell transplantation in patients with delayed-onset mustard gas keratopathy.
}

\section{Shiva Bagheri}

Semnan University Of Medical Sciences https://orcid.org/0000-0002-6442-9696

Seyed-Hashem Daryabari

Baqiyatallah University of Medical Sciences

Hossein Aghamollaei

Baqiyatallah University of Medical Sciences

Khosrow Jadidi ( $\boldsymbol{\sigma}$ kh.jadidi@gmail.com )

Baqiyatallah University of Medical Sciences https://orcid.org/0000-0002-2503-3322

Research

Keywords: sulfur mustard, lamellar keratoplasty, limbal stem cell

Posted Date: November 13th, 2020

DOl: https://doi.org/10.21203/rs.3.rs-106469/v1

License: (c) (1) This work is licensed under a Creative Commons Attribution 4.0 International License.

Read Full License 


\section{Abstract}

Background: Iran is one of the biggest chemical warfare victims in the world and mustard gas keratopathy is a common complication in this rare injury. in recent years, finding an effective and uncomplicated corneal transplantation method has been a concern for ophthalmologists. In this study, we report the results of lamellar Keratoplasty (LK) without limbal stem cell transplantation in patients with delayed-onset mustard gas keratopathy (DMGK).

Methods: Thirty-one eyes of 22 veterans with DMGK who underwent conventional LK were included. The presence of limbal stem cell deficiency (LSCD) was proven clinically and so by impression cytology. The results were evaluated with respect to Best spectacle-corrected visual acuity (BSCVA), refractive error (RE), corneal clarity and corneal graft survival rates.

Results: The mean age of patients at the time of surgery was $52.93 \pm 5.8$ years and the mean follow-up duration was $36.25 \pm 20.65$ months. The mean preoperative BSCVA was $1.67 \pm 0.32$ logarithm of the minimal angle of resolution unit (Log MAR), which significantly improved and reached $0.32 \pm 0.22$ Log MAR after surgery. The mean preoperative spherical equivalent RE was $2.47 \pm 1.17$ diopters which increased to $3.5 \pm 1.08$ diopters after complete suture removal. Epithelial graft rejection occurred in $9.67 \%$ of eyes (3/31) and was treated successfully with topical eye drops. at the end of follow-up period, no signs of graft rejection were found but two eyes had mild central corneal opacity.

Conclusions: According to the results of this study, LK without LSC transplantation, can be successful in patients with DMGK, because of partial rather than complete LSCD.

\section{Background}

Sulfur mustard is an alkylating chemical warfare agent that was first used as a weapon of mass destruction in World War I in 1917 [1, 2]. The most recent use of this agent was in Iraq-Iran war, where it was used against Iranian forces and about 100,000 people sustained chemical injuries [3, 4]. The eyes are the most susceptible tissue to mustard gas, and depending on the extent of exposure, different parts of the eye including eyelids, conjunctiva, and especially the cornea will be damaged. Ocular complications occur immediately after the initial contact, and the symptoms include pain, tearing, photophobia and severe blepharospasm that usually improve after a few weeks (acute phase); however, in some patients, eye manifestations will not resolve and progress to a chronic phase. Late corneal involvement may occur one to 40 years after the initial contact with mustard gas and is known as delayed-onset mustard gas keratopathy (DMGK) $[5,6]$. This keratopathy causes a wide range of ocular complications, including dry eye, chronic photophobia, decreased vision, conjunctival vessel changes, limbal ischemia, limbal stem cell deficiency, corneal thinning and opacity, corneal scarring and neovascularization, lipid and amyloid deposition and corneal melting [6-11]. In some patients, the chronic and delayed effects of mustard gas reduce the vision severely necessitating procedures such as penetrating or lamellar keratoplasty depending on the depth of the lesion [12]. 
In most patients with DMGK, corneal involvement is limited to the anterior surface of the cornea and the posterior segment and endothelium remain healthy [13]. Moreover, the risk of graft failure after penetrating keratoplasty (PK) is high due to inflammation and vascularization of the cornea. Therefore, conventional lamellar Keratoplasty (LK) is the preferred treatment in these patients. Nevertheless, in selective cases, where there is excessive corneal thinning and total corneal involvement, total thickness transplantation is the selective treatment $[12,14]$. On the other hand, we know that different degrees of LSCD are observed in patients with chronic or Delayed MGK $[6,11,15-17]$. When there is a significant LSCD or limbal ischemia or both, stem cell transplantation is an effective way to provide a source for corneal epithelial cells and prevent conjunctival epithelial growth (conjunctivalization) and corneal thinning [18].

Interestingly, some chemical veterans have concurrent LSCD and corneal involvement, and previous studies have shown that stem cell transplantation is effective in improving the results of keratoplasty, and performing both methods simultaneously can be helpful in enhancing the transplant results $[19,20]$.

However, chemical veterans with DMGK may also suffer from systemic problems due to mustard gas exposure, such as lung injuries [21-23], thus administration of immunosuppressant and systemic steroids, which are used for a long time after stem cell transplantation, can lead to worsening of the general condition of these patients [24]. So, development of the method for transplantation without the need for immunosuppressant will be very attractive.

In contrast to the previous studies, in this study we performed corneal transplantation in patients with partial LSCD without stem cell transplantation and followed up the graft survival rate for about three years after LK. Here, we reported the results of lamellar Keratoplasty without LSC transplantation in patients with delayed-onset mustard gas keratitis.

\section{Methods}

In this long-term retrospective study, 31 eyes from 22 victims of chemical warfare who were chemically injured in the Iran-Iraq war (between 1980 and 1988) were examined in the Baqiyatallah hospital, Tehran, Iran. Because Iran is one of the biggest victims of chemical warfare and there are many chemical casualties in Iran, the selection of cases is based on the experience of the authors who examined and studied these rare patients for many years after the Iran-Iraq war.

All of our participants had DMGK, and the corneal involvement was so severe that they required LK, according to an expert ophthalmic surgeon (K.J).

This study was approved by medical ethics committee of Baqiyatallah university of medical sciences.

The partial stem cell deficiency was diagnosed clinically in all patients by observing the epithelial defect, stromal inflammation, corneal neovascularization, conjunctival epithelial growth and corneal opacification [Fig. 1] and in 10 eyes, using impression cytological analysis [Fig. 2]. 
Although sampling for impression cytology was done under local anesthesia, but corneal epithelial defect is induced after this method. This defect is difficult to heal with conventional treatments, so impression cytology was not performed for all patients.

A complete history, including sex, age, time of exposure to mustard gas, ocular symptoms, ophthalmic and systemic medications, systemic diseases, and history of any ocular or systemic surgery was taken from the patients.

In all patients, preoperative refractive error (RE) and best spectacle-corrected visual acuity (BSCVA) was measured and patients underwent slit-lamp biomicroscopy to assess the corneal status, tear meniscus rate, and intra ocular pressure (IOP), finally dilated funduscopy was performed for all patients.

All patients underwent LK surgery without stem cell transplantation, and all surgeries were performed by the same surgeon (K.J). Patients were followed up post-operatively every week for the first month, then monthly for up to one year and every 3 months thereafter. In each follow-up visit the RE, BSCVA, IOP values were measured and slit-lamp bio microscopic examinations were repeated and graft clarity was evaluated. Slit lamp photographs were also taken before and after the operation.

\section{Lamellar Keratoplasty}

Indications for LK were decreased visual acuity, irritation and photophobia caused by corneal opacity, severe corneal thinning, abnormal deposits or a combination of these with a normally functioning endothelium. All patients studied had LK surgery indications.

Patients were first subjected to general anesthesia. The cornea was thoroughly washed with the saline solution and the size of the area that needed to be removed was determined. A Barron Hesburgh suction trephine was used for trephination of the recipient cornea, and cornea was scraped layer-by-layer by crescent blade to reach the deep stroma. To create a smooth and clear recipient bed, the removal process was continued until the cornea became completely clear and no scar or deposit was observed.

The donor cornea was cut approximately $0.5 \mathrm{~mm}$ larger than the recipient diameter with a Hesburgh Barron punch, then the endothelium of the cornea was removed and placed on the recipient eye. Then it is sutured with nylon suture 10.0 to recipient bed. Our suture technique was mostly single running sutures and in some cases as interrupted sutures.

After the transplantation surgery, patient's punctum was cauterized if it was not already closed, and lateral tarsoraphy was performed in all patients. The patient was examined the next day, and the appropriate medications were prescribed.

\section{Post-operation Phase}

After the surgery, $0.1 \%$ betamethasone topical eye drops were given every 6 hours, and were tapered off after 6 months. $0.3 \%$ ciprofloxacin drops were given every 4 hours for a week, and preservative free 
lubricant was administered every 2 hours for one week up to a year based on patient's condition. Sutures were not routinely removed for a year post-operatively. After one year, we selectively removed stitches based on refractive error and corneal stigmatization rate. In patients who had single running sutures, the sutures were not removed unless the sutures became loose.

\section{Statistical analysis}

The rate of corneal graft survival was measured in patients three years after surgery. Statistical analysis was carried out using SPSS software version 20 (SPSS for windows, Chicago, IL). In order to evaluate the distribution of two qualitative variables $\mathrm{chi}^{2}$ test was used. For quantitative variables, Kolmogorov Smirnoff test was used to assess the normality. If data was normally distributed the independent $T$ test was used otherwise the equivalent non parametric test was used. Level of significance was set at $p$ value $<0.05$.

\section{Results}

Our study included 31 eyes from 22 patients (all male) with DMGK who were more than 30 years after when they were exposed to mustard gas. At the time of the LK operation, the mean age of these individuals was $52.93 \pm 5.8$ years (range $38-62$ years), and the mean duration of postoperative follow-up was $36.25 \pm 20.65$ months (range 12-72 months).

Preoperative slit lamp examinations showed chronic blepharitis and varying degrees of dry eye in all patients. IOP was normal in all patients. In corneal evaluation, we observed peripheral and paracentral thinning of corneal stoma in $38.7 \%$ (12/31) of eyes. Also corneal opacity, neovascularization and lipid or amyloid deposition was seen in $32.2 \%(10 / 31), 32.2 \%(10 / 31)$ and $29 \%(9 / 31)$ of cases respectively.

The average BSCVA before surgery was $1.67 \pm 0.32$ logarithm of the minimum angle of resolution (log MAR) units, ranging from 2.09 to 1.22 log MAR units, that significantly improved and reached $0.32 \pm 0.22$ $\log M A R$, ranging from 1 to $0.8 \log$ MAR units after surgery $(p=0.001)$. The mean spherical equivalent refractive error before the operation was $2.47 \pm 1.17 \mathrm{D}$, which reached $3.5 \pm 1.08 \mathrm{D}$ after the operation $(p=$ 0.001). The refractive error was measured at least three months after the last suture was removed.

In all patients studied, partial limbal stem cell deficiency was confirmed by using clinical criteria.

Cytological impression was performed in $32 \%$ (10/31) of the eyes with clinical signs of LSCD, and the analysis showed the presence of goblet cells in at least a quarter of the cornea [Fig. 2].

We did not find any case of severe squamous metaplasia or conjunctival intraepithelial neoplasia but, mild to moderate squamous metaplasia observed in $60 \%(6 / 10)$ of these cases.

Preoperative symptoms were decreased vision, photophobia, dry eye and foreign body sensation. After surgery $77.4 \%(24 / 31)$ of these patients are satisfied due to reduced symptoms. 
Epithelial graft rejection was observed in $9.67 \%(3 / 31)$ of eyes after keratoplasty, which was successfully treated with $0.1 \%$ betamethasone topical drops.

Interface vascularization was observed in $6.4 \%(2 / 31)$ of eyes and also, peripheral scar formation was seen in $9.6 \%(3 / 31)$ of eyes.

None of the patients demonstrated evidence of graft rejection, however $6.4 \%(2 / 31)$ of eyes have mild central corneal opacity in postoperative examinations.

The following figures show some of the eyes that underwent LK surgery [Fig. 3-6].

Due to the special circumstances of these patients and their constant need for medical care under the supervision of a physician, all patients were present during the follow-up period and none were lost.

\section{Discussion}

Approximately 100,000 chemical warfare victims live in Iran, and about $0.5 \%$ of them suffer from severe DMGK $[25,26]$. Since no definitive methods exist for treating chronic or Delayed MGK, therapeutic methods in patients with this rare complication depends on the type and severity of the disease and include treatments to improve symptoms and dry eye, as well as stem cell and corneal transplantation [7, 27].

We know that whenever corneal changes and progressive thinning of the cornea reduce vision or cause eye irritation, corneal transplantation becomes necessary [28].

Because most DMGK patients have corneal involvement in the anterior part, and the corneal endothelium is healthy [13], conventional LK is a suitable treatment [14], And according to our experience deep anterior lamellar keratoplasty using the big bubble technique is difficult in these patients, because of difficulties in separating the Descemet's membrane from stroma perhaps due to alterations in the corneal stroma as a result of corneal inflammation, corneal scar, and or lipid and amyloid deposits. therefore, it was not performed in these patients.

On the other hand, mustard gas chemical injuries result in different degrees of LSCD, and this complication is one of the causes of DMGK $[29,30]$. Stem cell defects results in conjunctivalization of the cornea with vascularization, as well as the appearance of goblet cells and the formation of an irregular and unstable epithelium stem cell transplantation which will cause eye irritation and reduced vision, therefore stem cell transplantation is required to treat these patients [31]. Previous studies have shown that stem cell transplantation is effective in improving the results of LK surgery in patients with DMGK, and results of the simultaneous approach is better than staged intervention $[19,20]$.

On the other hand, by using impression cytology and clinical examination we found that LSCD is partial in chemical injuries and is more common in the eyelid fissure area (in the nasal and temporal cornea), where cornea is more exposed. These observations are consistent with the results of another study 
conducted previously by Baradaran-Rafii and colleagues using impression cytology. They stated that in DMGK, the severity of corneal clinical manifestations is higher in the nasal and temporal zones, and initially localized LSCD is more common than total LSCD in chemical veterans [15].

Due to concomitant systemic problems, such as respiratory injuries, in chemical veterans [32], long-term use of systemic immunosuppressant after stem cell transplantation can exacerbate their condition and cause serious complications.

In two of our experienced samples in the past, after stem cell transplantation and following long-term systemic immunosuppression, patients developed lung infection with cytomegalovirus (data not shown).

Considering the aforementioned delicate condition of these patients and the presence of partial stem cell defects we performed conventional LK alone in our study population. We followed our patient for a mean of three years after surgery and showed that no signs of graft rejection or graft failure were evident in the slit-lamp biomicroscopic examinations.

According to our results, corneal transparency and transplant survival after LK without stem cell transplantation in DMGK patients is desirable if there is partial LSCD. Moreover, using LK without stem cell transplantation does not require long-term treatment with systemic immunosuppressive drugs, and will remove the unnecessary risk of complication with these drugs in patients with mustard gas chemical injuries, who usually suffer from other conditions especially lung problems. On the other hand, the risk of glaucoma and cataract that occur after long-term use of local steroids is reduced in these patients.

Furthermore, no evidence of exacerbations was observed in postoperative follow-up examinations and no new signs of mustard gas activity were found in our study population. In all of these patients, our examinations and evaluations will continue, as many questions about this rare DMGK complication still remains, and more research is needed on its exact nature and pathophysiology.

Our study had several limitations. For instance, we did not perform impression cytology analysis in all subjects and also after LK, and in postoperative periodic examinations, the status of stem cells was assessed only by bio microscopic examination and photo-slit images. Finally, more time is required for the follow-up of these rare patients, and we will regularly review graft clarity and stem cell status in these patients and hope to be able to report 5-year and 10-year results in future studies.

\section{Conclusion}

According to our results, conventional lamellar keratoplasty alone, is acceptable surgical method for corneal and limbal involvements in delayed-onset mustard gas keratopathy, due to partial LSCD.

\section{Abbreviations}

Lk: lamellar keratoplasty 
DMGK: delayed-onset mustard gas keratopathy

BSCVA: best spherical corrected visual acuity

RE: refractive error

Log MAR: logarithm of the minimal angle of resolution

PK: penetrating keratoplasty

IOP: intra ocular pressure

D: diopter

\section{Declarations}

\section{Ethics approval and consent to participate}

The ethics committee of Baqiyatallah University of Medical Sciences approved the study protocol, which was conducted in accordance with the tenets of the Helsinki Declaration. All participants signed a written informed consent.

\section{Consent of publication}

Not applicable

\section{Availability of data and materials}

The datasets used and/or analyzed during the current study are available from the corresponding author on reasonable request.

\section{Competing interest}

The authors declare that they have no competing interests

\section{Funding}

Not applicable

\section{Authors contributions}

designed research and wrote the manuscript: SHB, SHD. Collected and analyzed data.: HA. designed research and performed study: KHJ. The authors read and approved the final manuscript.

\section{Authors information:}

\section{Affiliations:}


Shiva Bagheri, Khosrow Jadidi

Vision Health Research Center, Semnan university of medical sciences, Semnan,Iran

Seyed-Hashem Daryabari, Hossein Aghamollaei

Chemical Injuries Research Center, Systems biology and Poisonings Institute, Baqiyatallah University of Medical Sciences, Tehran, Iran.

\section{Corresponding author}

Correspondence to Khosrow Jadidi.

\section{Acknowledgment}

Not applicable

\section{References}

1. Blewett W. Tactical weapons: is mustard still king. NBC Defense Technol Int. 1986;1:64-6.

2. Solberg Y, Alcalay M, Belkin M. Ocular injury by mustard gas. Survey of ophthalmology. 1997;41(6):461-6.

3. Ghasemi H, Ghazanfari T, Babaei M, Soroush MR, Yaraee R, Ghassemi-Broumand M, et al. Long-term ocular complications of sulfur mustard in the civilian victims of Sardasht, Iran. Cutaneous and ocular toxicology. 2008;27(4):317-26.

4. Namazi S, Niknahad H, Razmkhah H. Long-term complications of sulphur mustard poisoning in intoxicated Iranian veterans. Journal of medical toxicology. 2009;5(4):191.

5. Javadi M-A, Yazdani S, Sajjadi H, Jadidi K, Karimian F, Einollahi B, et al. Chronic and delayed-onset mustard gas keratitis: report of 48 patients and review of literature. Ophthalmology. 2005;112(4):61725. e2.

6. Baradaran-Rafii A, Eslani M, Tseng SC. Sulfur mustard-induced ocular surface disorders. The ocular surface. 2011;9(3):163-78.

7. Rajavi Z, Safi S, Javadi MA, Jafarinasab MR, Feizi S, Moghadam MS, et al. Clinical practice guidelines for prevention, diagnosis and management of early and delayed-onset ocular injuries due to mustard gas exposure. Journal of ophthalmic \& vision research. 2017;12(1):65.

8. Panahi Y, Naderi M, Zare MA, Poursaleh Z. Ocular effects of sulfur mustard. Iranian Journal of Ophthalmology. 2013;25(2):90.

9. Rowell M, Kehe K, Balszuweit F, Thiermann H. The chronic effects of sulfur mustard exposure. Toxicology. 2009;263(1):9-11.

10. Ghasemi H, Ghazanfari T, Ghassemi-Broumand M, Javadi MA, Babaei M, Soroush MR, et al. Longterm ocular consequences of sulfur mustard in seriously eye-injured war veterans. Cutaneous and 
ocular toxicology. 2009;28(2):71-7.

11. Safarinejad M, Moosavi S. Ocular injuries caused by mustard gas: diagnosis, treatment, and medical defense. Military medicine. 2001;166(1):67-70.

12. Javadi MA, Yazdani S, Kanavi MR, Mohammadpour M, Baradaran-Rafiee A, Jafarinasab MR, et al. Long-term outcomes of penetrating keratoplasty in chronic and delayed mustard gas keratitis. Cornea. 2007;26(9):1074-8.

13. Jafarinasab M-R, Zarei-Ghanavati S, Kanavi MR, Karimian F, Soroush M-R, Javadi M-A. Confocal microscopy in chronic and delayed mustard gas keratopathy. Cornea. 2010;29(8):889-94.

14. Feizi S, Javadi MA, Jafarinasab MR, Karimian F. Penetrating keratoplasty versus lamellar keratoplasty for mustard gas-induced keratitis. Cornea. 2013;32(4):396-400.

15. Baradaran-Rafii A, Javadi M-A, Kanavi MR, Eslani M, Jamali H, Karimian F. Limbal stem cell deficiency in chronic and delayed-onset mustard gas keratopathy. Ophthalmology. 2010;117(2):24652.

16. Javadi M-A, Baradaran-Rafii A. Living-related conjunctival-limbal allograft for chronic or delayedonset mustard gas keratopathy. Cornea. 2009;28(1):51-7.

17. Nishiwaki-Dantas MC, Dantas PEC, Reggi JRA. Ipsilateral limbal translocation for treatment of partial limbal deficiency secondary to ocular alkali burn. British journal of ophthalmology. 2001;85(9):10313.

18. Huang T, Wang Y, Zhang H, Gao N, Hu A. Limbal allografting from living-related donors to treat partial limbal deficiency secondary to ocular chemical burns. Archives of Ophthalmology. 2011;129(10):1267-73.

19. Jafarinasab MR, Feizi S, Javadi MA, Karimian F, Soroush MR. Lamellar keratoplasty and keratolimbal allograft for mustard gas keratitis. American journal of ophthalmology. 2011;152(6):925-32. e2.

20. Javadi M, Jafarinasab M, Feizi S, Karimian F, Amoohashemi N. Management of Complications of Mustard Gas Keratitis with Corneal and Limbal Stem Cell Transplantation. 2012.

21. Khateri S, Ghanei M, Keshavarz S, Soroush M, Haines D. Incidence of lung, eye, and skin lesions as late complications in 34,000 Iranians with wartime exposure to mustard agent. Journal of occupational and environmental medicine. 2003;45(11):1136-43.

22. Ghassemi-Broumand M, Aslani J, Emadi S-N. Delayed ocular, pulmonary, and cutaneous complications of mustards in patients in the city of Sardasht, Iran. Cutaneous and ocular toxicology. 2008;27(4):295-305.

23. mansour Razavi S, Salamati P, Saghafinia M, Abdollahi M. A review on delayed toxic effects of sulfur mustard in Iranian veterans. DARU Journal of Pharmaceutical Sciences. 2012;20(1):51.

24. Behaegel J, Ní Dhubhghaill S, Koppen C, Zakaria N. Safety of cultivated limbal epithelial stem cell transplantation for human corneal regeneration. Stem cells international. 2017;2017. 
25. Razavi SM, Razavi MS, Pirhosseinloo M, Salamati P. Iraq-Iran chemical war: calendar, mortality and morbidity. Chinese journal of traumatology. 2014;17(3):165-9.

26. Javadi MA. Mustard gas induced ocular injuries. Journal of ophthalmic \& vision research. 2017;12(1):1.

27. Kadar T, Dachir S, Cohen L, Sahar R, Fishbine E, Cohen M, et al. Ocular injuries following sulfur mustard exposure-pathological mechanism and potential therapy. Toxicology. 2009;263(1):59-69.

28. Richter MN, Wachtlin J, Bechrakis NE, Hoffmann F. Keratoplasty after mustard gas injury: clinical outcome and histology. Cornea. 2006;25(4):467-9.

29. Kadar T, Horwitz V, Sahar R, Cohen M, Cohen L, Gez R, et al. Delayed loss of corneal epithelial stem cells in a chemical injury model associated with limbal stem cell deficiency in rabbits. Current eye research. 2011;36(12):1098-107.

30. Kadar T, Dachir S, Cohen M, Gutman H, Cohen L, Brandeis R, et al. Prolonged impairment of corneal innervation after exposure to sulfur mustard and its relation to the development of delayed limbal stem cell deficiency. Cornea. 2013;32(4):e44-e50.

31. Dua HS, Azuara-Blanco A. Limbal stem cells of the corneal epithelium. Survey of ophthalmology. 2000;44(5):415-25.

32. Ghanei M, Amini Harandi A. The respiratory toxicities of mustard gas. Iranian Journal of Medical Sciences. 2010;35(4):273-80.

\section{Figures}

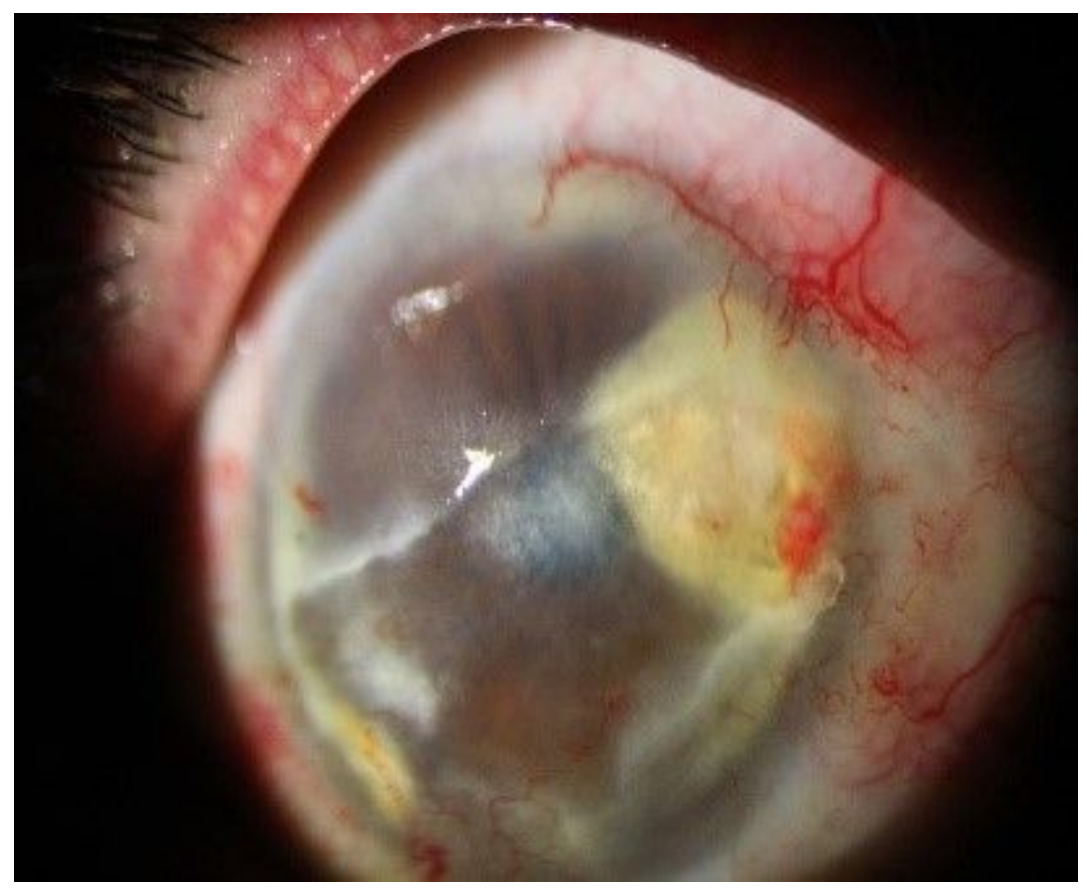

Figure 1 
image showing limbal stem cell deficiency caused by mustard gas. normal epithelium replaced with conjunctival epithelium, resulting in corneal neovascularization and opacification.

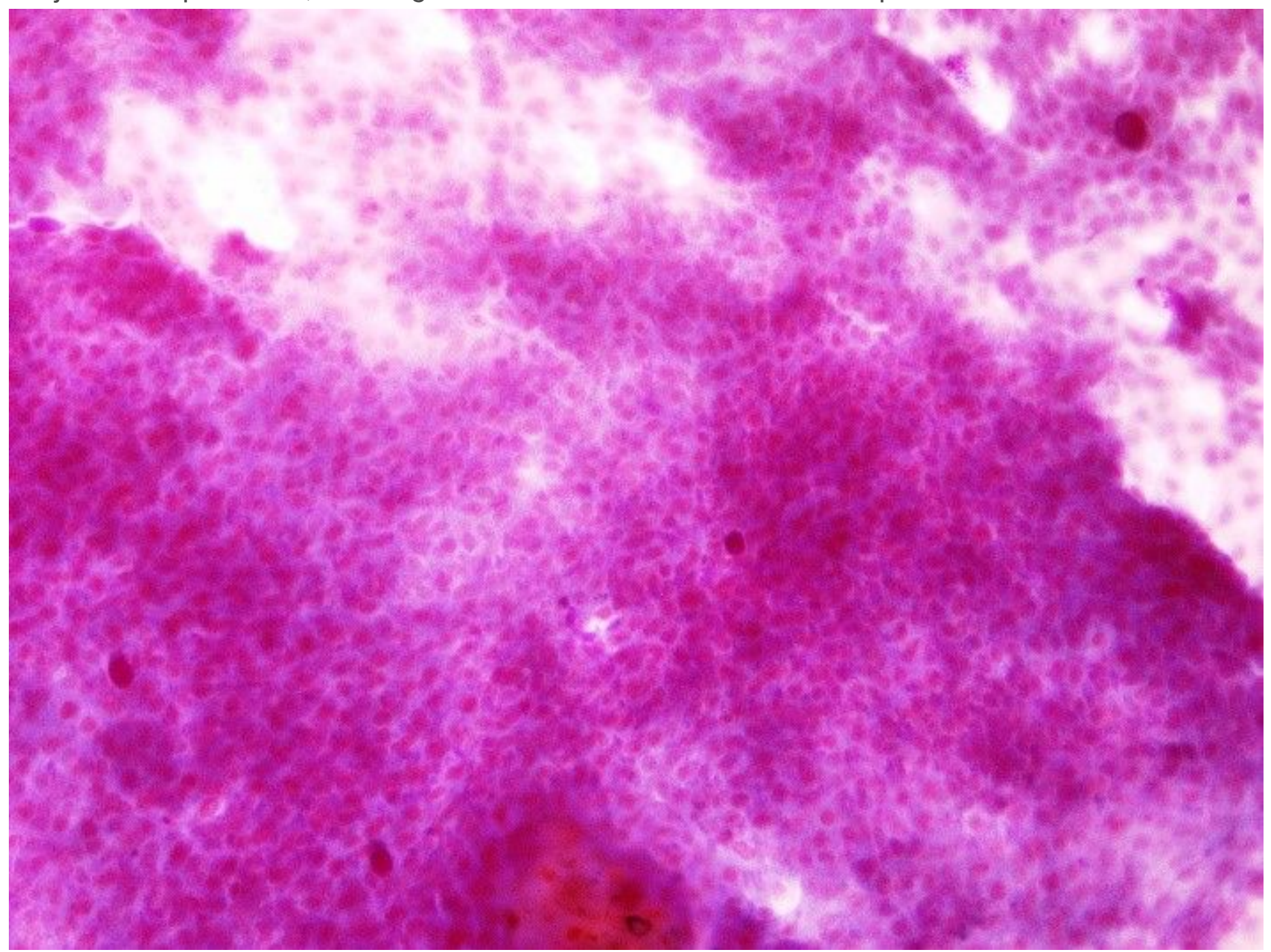

\section{Figure 2}

corneal impression cytology results in a patient with delayed-onset mustard gas keratopathy showing corneal epithelial cells with marked conjunctivalization and presense of some goblet cells, modified pas staining $\times 100$. 


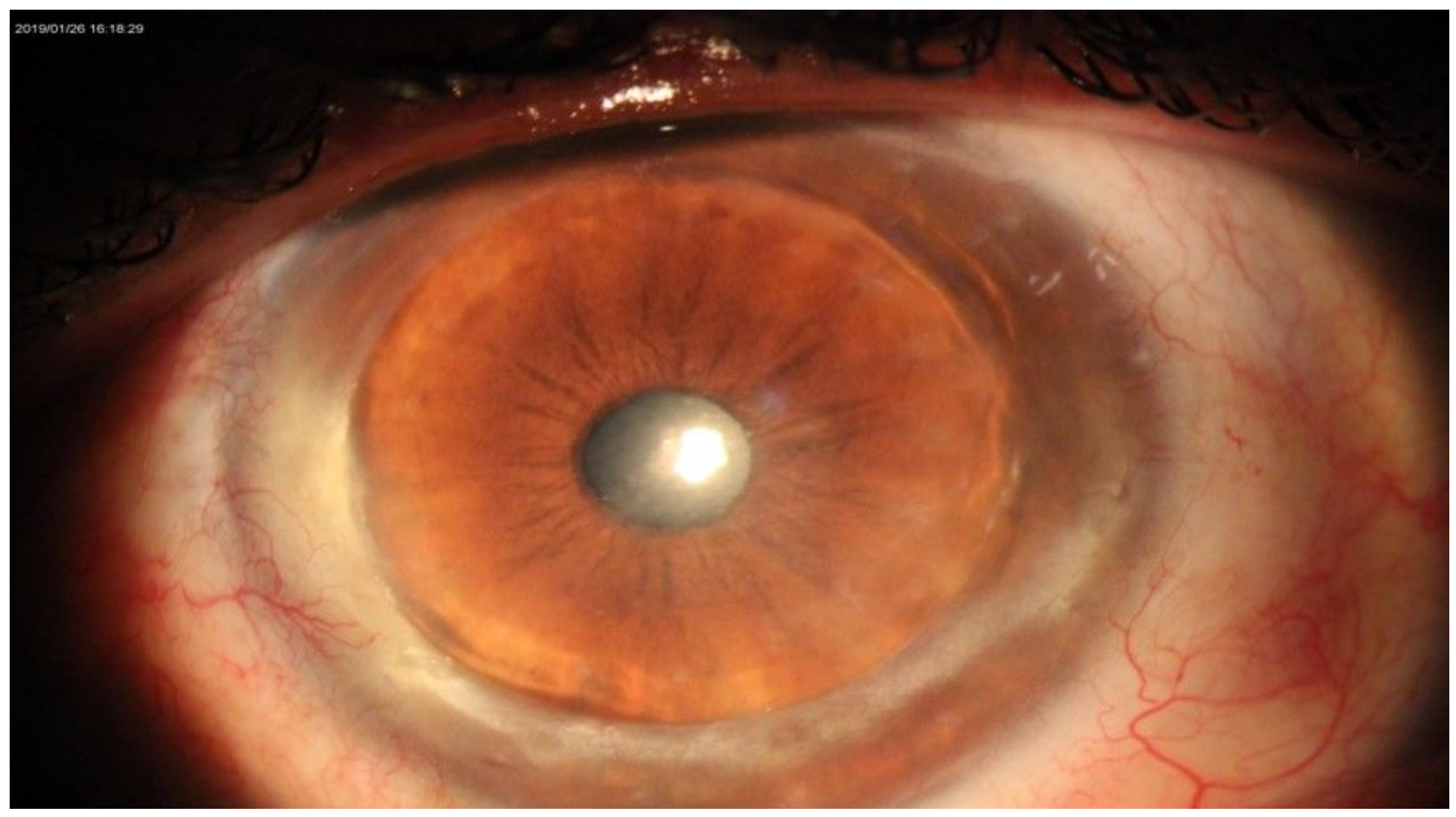

\section{Figure 3}

images showing graft clarity about 3 years after lamellar keratoplasty for mustard gas keratitis in patients with partial limbal stem cell deficiency. 


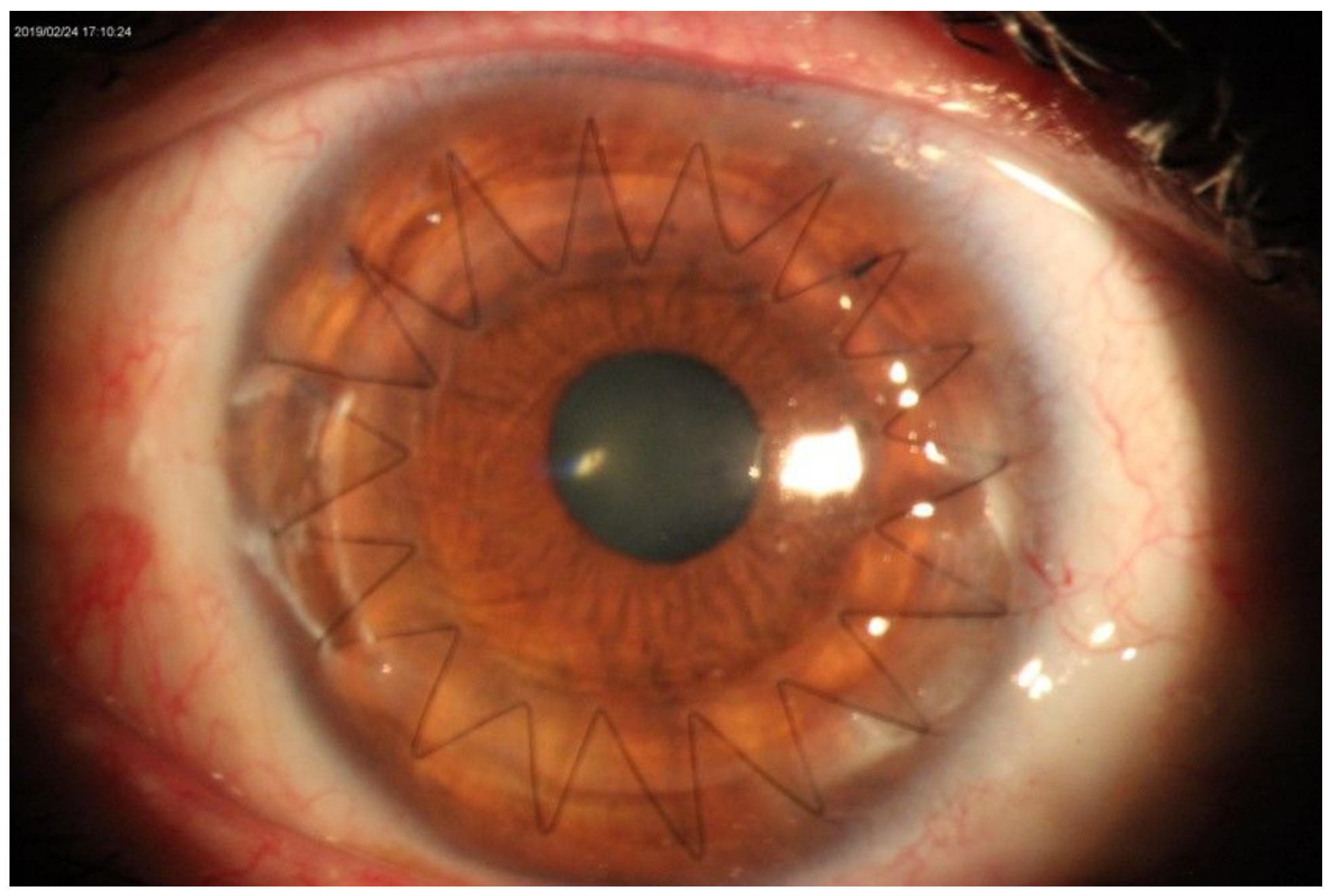

\section{Figure 4}

images showing graft clarity about 3 years after lamellar keratoplasty for mustard gas keratitis in patients with partial limbal stem cell deficiency. 


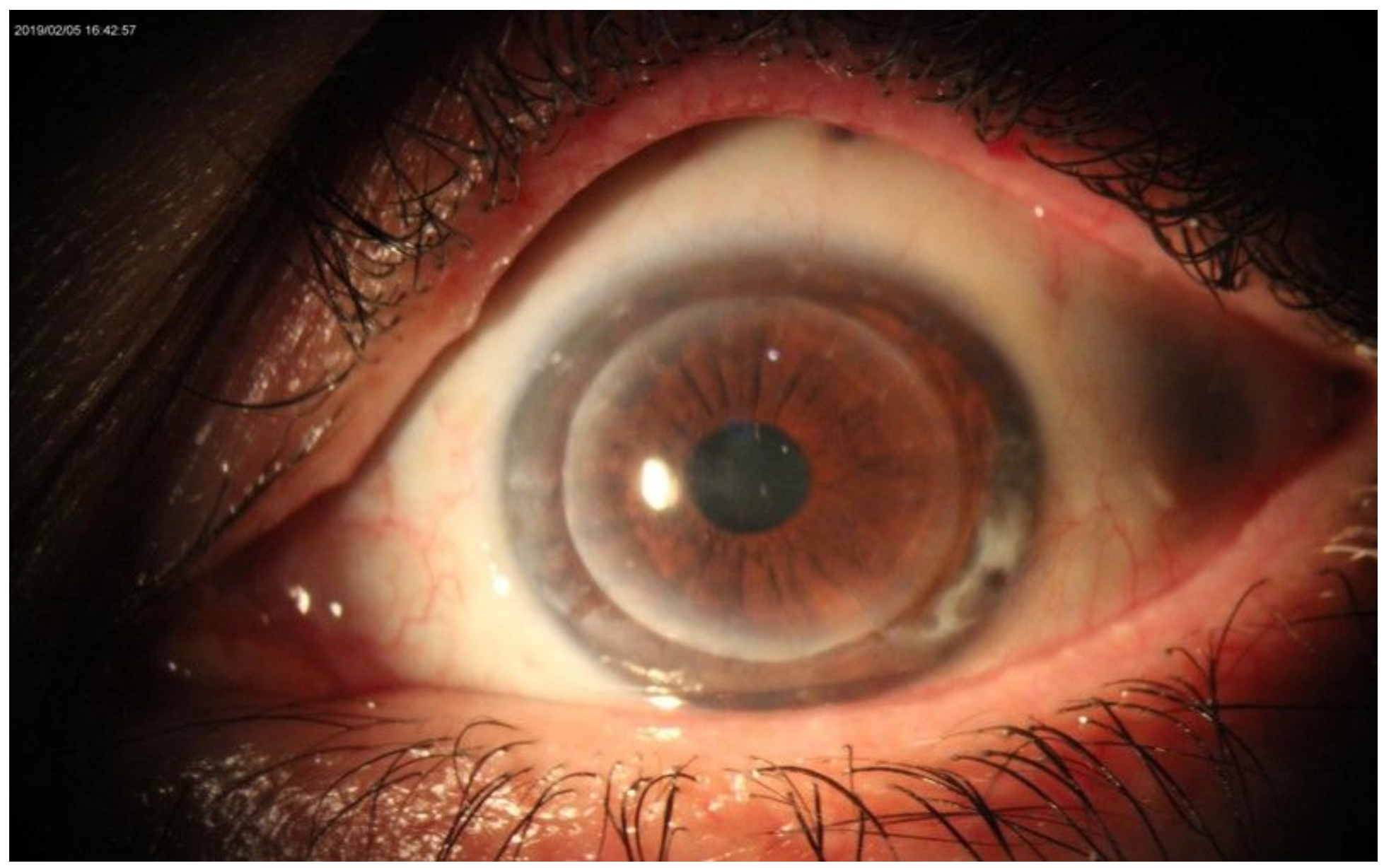

\section{Figure 5}

images showing graft clarity about 3 years after lamellar keratoplasty for mustard gas keratitis in patients with partial limbal stem cell deficiency. 


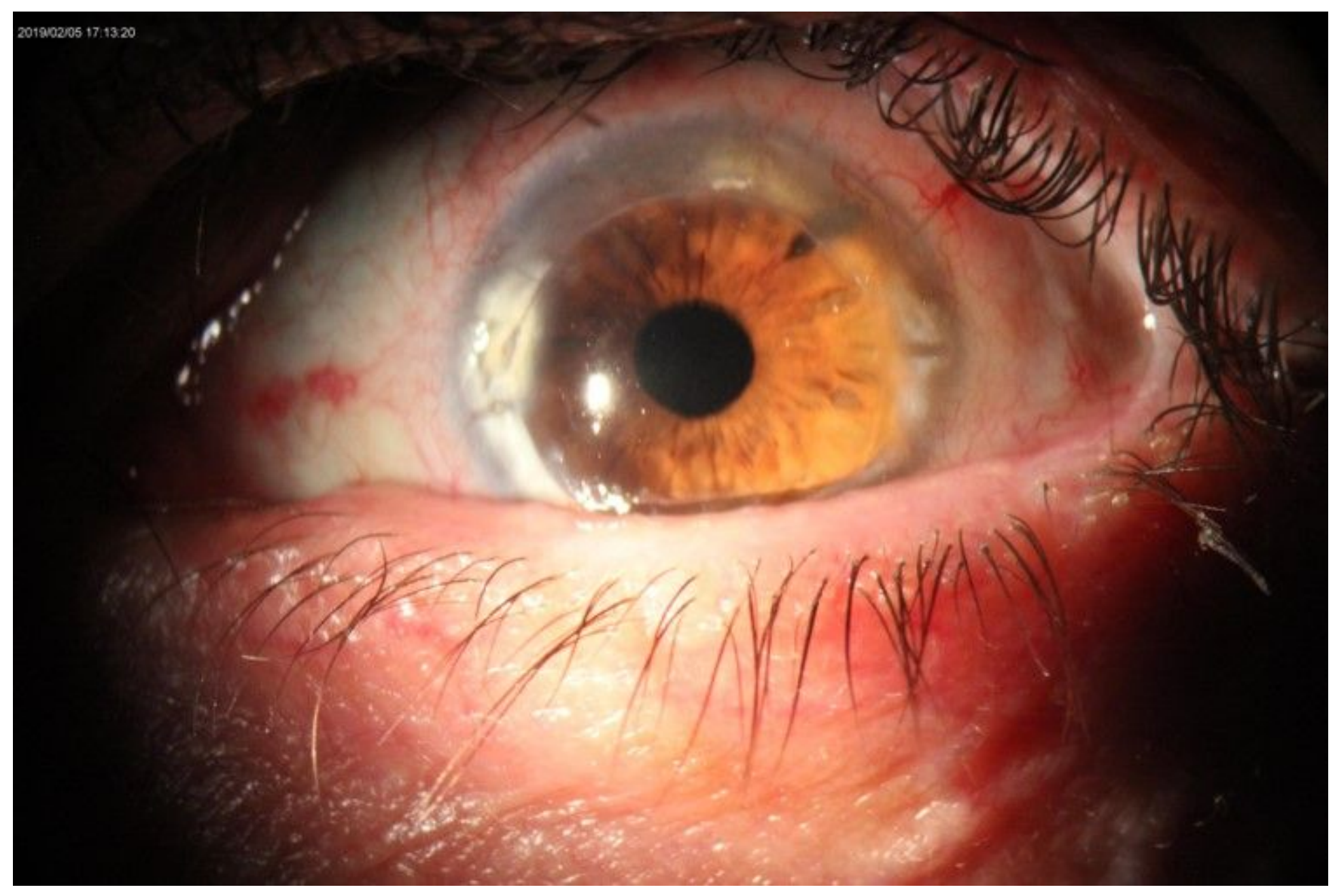

\section{Figure 6}

images showing graft clarity about 3 years after lamellar keratoplasty for mustard gas keratitis in patients with partial limbal stem cell deficiency. 